\title{
Fabrication of barium titanate by binder jetting additive manufacturing technology
}

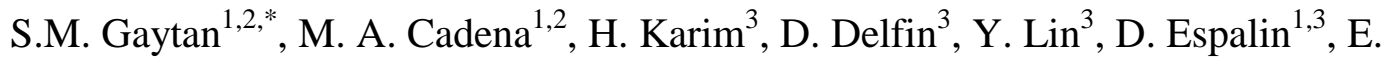

MacDonald $^{1,4}$, R.B. Wicker ${ }^{1,3}$

${ }^{1}$ The W.M. Keck Center for 3D Innovation, El Paso, Texas University of Texas at El Paso, El Paso, Texas, USA

${ }^{2}$ Metallurgical and Materials Engineering Department, The University of Texas at El Paso, El Paso, Texas, USA

${ }^{3}$ Mechanical Engineering Department, The University of Texas at El Paso, El Paso, Texas, USA

${ }^{4}$ Electrical and Computer Engineering Department, The University of Texas at El Paso, El Paso, Texas, USA

* Corresponding author. Tel.: +1 (915) 747-6391; fax: +1 (915) 747-5019; e-mail address: smgaytan@utep.edu

\begin{abstract}
Fabrication of barium titanate $\left(\mathrm{BaTiO}_{3}\right)$ specimens was accomplished with binder jetting additive manufacturing, and build parameters (e.g. binder saturation and layer thickness) and sintering profiles were modified to optimize the density achieved and the crystal structures obtained in the 3D printed parts. Surface and cross sectional grain morphology was characterized by scanning electron microscopy (SEM) revealing grain growth on localized areas of BTO fabricated specimens after sintering. Crystal structure was analyzed by X-ray diffraction (XRD) where the presence of a hexagonal phase was observed for


$\mathrm{BaTiO}_{3}$ only when sintered at $1400^{\circ} \mathrm{C}$. The dielectric constant of the fabricated $\mathrm{BaTiO}_{3}$ specimens sintered at $1260^{\circ} \mathrm{C}$ was obtained by using a $\mathrm{K}_{\mathrm{u}}$-band wave-guide and vector network analyzer setup in which the relative permittivity was measured from 8.6 to 6.23 for a frequency range of 12.4 to $18 \mathrm{GHz}$, respectively. When sintered at $1400^{\circ} \mathrm{C}$ for 4 hours, a density of $3.93 \mathrm{~g} / \mathrm{cm}^{3}$ was obtained, which corresponds to $65.2 \%$ of the theoretical density. Piezoelectric properties exhibited a $\mathrm{d}_{33}$ value of 74.1 for specimens also sintered at $1400^{\circ} \mathrm{C}$. Results reported in this paper demonstrate the feasibility of BTO as a binder jetting material for 3D printed dielectric structures, ceramic capacitors and gas and pressure sensors.

Keywords: ceramics, 3D printing, characterization, dielectric constant, piezoelectric

\subsection{Introduction}

Among several ceramics used for their ability for polarization is the dielectric $\mathrm{BaTiO}_{3}$ (BTO) with applications varying from chip capacitors to dynamic random access memories [1], and embedded capacitance in printed circuit boards to piezoelectric devices like sensors, heaters and transducers [2] [3]. Other applications that use BTO for ferroelectric and piezoelectric properties include semiconductors with positive temperature coefficient of resistivity (PTCR) [4], dynamic access memories (DRAM), and IR sensors [5]. $\mathrm{BTO}$ has a curie temperature at $120^{\circ} \mathrm{C}$ and depending on its crystal structure, $\mathrm{BTO}$ can be para-electric (cubic; $a=4.031 \AA$ ) or ferroelectric (tetragonal; $a=3.994 \AA$ and $c=4.038 \AA$ ) [6] [3], which are desired structures for sensor applications due to the properties provided (pyroelectric and piezoelectric). [7] stated that BTO has the largest dielectric constant 
when being near the ferroelectric phase due to polarization from ion displacement or the alignment of permanent dipoles.

Some deposition methods used for BTO are vacuum evaporation, sputtering, laser ablation, hydrothermal synthesis, radio frequency plasma sputtering and sol-gel techniques used for BTO thin films preparation [8]. Some of these techniques still have drawbacks since cracking and peeling of the deposited layers occurs during the final heat-treating process, which is required to crystallize the as-deposited amorphous film [9]. The methods previously mentioned are designed for the fabrication of thin films where powder is in the nano-range or as a stable colloidal solution. One method used for the fabrication of undoped $\mathrm{BaTiO}_{3}$ ceramics is by slip casting of slurries or sol-gel solutions to create thin dielectric layers [10] [11] [12]. Even when research has been pursued to improve dielectrics such as barium titanate, attempts have been made via 3D printing for this material like the use of inkjet printing to create capacitors with a low volume of polymer ink [13], and the fabrication of 3D piezoelectric BTO nanoparticles embedded in a polyethylene glycol diacrylate matrix by digital projection printing where $\mathrm{d}_{33}$ values of 40 pC/N were obtained for a maximum particle loading of 10wt\% [14] [15]. Also, fabrication of ferroelectric photoactive suspensions by stereolithography has been reported for maximum BTO ceramic volume of $40 \%$ in hexanediol diacrylate, which proved to have poor curing behavior due to the difference on surface reflectance of the ceramic and the resin used [16].

BTO has a melting temperature of $1654^{\circ} \mathrm{C}$. Sintering temperatures of 1200 and $1300^{\circ} \mathrm{C}$, for $1 \mathrm{~mm}$-thick specimens from powder particle size of $35 \mathrm{~nm}$ have been reported with a maximum grain growth of $2.2 \mu \mathrm{m}$ (6185.71\% grain growth) [17]. Sintering 
temperatures of $800^{\circ} \mathrm{C}$ applied for ten hours using $30 \mathrm{~nm}$ diameter BTO powders provided a theoretical density of $90 \%$ [2]. Density increase and sintering behavior for BTO ceramics is a continuously researched topic; one reason is the need for porous structures with gas and liquid permeability for humidity sensors [18]. For simple 3D printed parts, cold isostatic pressing is used to increase the density, but when the geometry is complex, the internal enclosed cavities have to be supported to prevent the collapse of the structure [19]. It is foreseen that fabrication of BTO by $3 \mathrm{D}$ printing will enhance current fabrication methods for pressure sensors and ultracapacitors. The dielectric material can be customized to the required geometries and mass produced, therefore, a cost reduction is also foreseen. Additionally, porous structures that have gas and liquid permeability can be fabricated for humidity sensors applications [18]. Additive manufacturing provides the advantage of modifying porosity size and porosity homogeneity as necessary for optimum properties of the sensor. In this study, a binder jetting technology was used to fabricate robust geometric specimens of $12 \times 12 \times 3 \mathrm{~mm}$ by using commercial BTO powder. Coupon specimens were fabricated with different binder saturation percentages and sintered at different temperatures in an attempt to obtain fully dense specimens. Part shrinkage was calculated and used to obtain accurate dimensions for dielectric constant measurements. XRD data showed no signs of contamination after sintering and corroborated the maximum sintering temperature allowed for BTO to remain in the cubic and tetragonal phases. Dielectric constant values were obtained and presented in this paper for a frequency range of 12.4 to $18 \mathrm{GHz}$. Since it is known that dielectric constant increases with smaller grain size or higher density [20], it is expected that dielectric constant values obtained in this project can be further increased if grain growth can be further minimized. It is expected 
that by increasing the density and, as previously mentioned, reducing the grain size, the dielectric and piezoelectric properties can be enhanced sufficiently to enable the manufacture of geometrically complex high-K dielectrics necessary for ultra-capacitors or conformal piezoelectric structures for customized energy harvesting applications.

BTO fabricated by 3D printing can provide the necessary means to create dielectrics for ultracapacitors in the bulk size, where an ultracapacitor with a capacitance of up to 5000 farads can measure up to $5 \times 5 \times 15 \mathrm{~cm}$. Ultracapacitors can be used in a number of functions for a car, such as the air conditioning, door locks, seats and windows, the seat adjustment mechanism, and in the acceleration and braking modules [21], the generator action of the piezoelectric ceramic can also be used in fuel-igniting devices, and solid state batteries. Additionally, BTO by binder jetting can be the next fabrication method for vibration control by the creation of piezoelectric systems with coupled actuators [22]. The

freedom of 3D printing can enable custom, conformal, geometrically-complex piezoelectric devices for next generation energy harvesting in the consumer, automotive, bio-medical, aerospace and defense industries. One transformative example includes the possibility of an energy-harvesting active bio-medical implant the shape of which could be customized for a unique human anatomical geometry (e.g. a bone implant for a specific patient that will eliminate the need for battery replacement and resulting follow-on surgeries).

\subsection{Materials and methods}

\subsection{Materials}

Spherical barium titanate (IV) $\left(\mathrm{BaTiO}_{3}\right)$ powder of +325 mesh $(0.85$ to $1.45 \mu \mathrm{m})$

(Fisher Scientific, USA) was used for fabrication by binder jetting, Figure 1a shows as- 
received powder where the presence of agglomerations and a binding agent can be visualized. Since powder sifting is not a feasible path to remove powder agglomerations due to the small powder size of BTO, it was determined to heat the BTO powder for one hour to a maximum temperature of $1000^{\circ} \mathrm{C}$ with a ramp up rate of $10^{\circ} \mathrm{C} / \mathrm{min}$ after fabrication for recycling purposes throughout the length of the project. Prior to heating the powder, it was noted that in order to achieve a uniform spread layer of BTO, it was necessary to level the powder bed and add $\sim 10$ extra layers of powder in order to avoid unfilled areas. Figure $1 \mathrm{~b}$ shows powder after heating, and even though the powder continues to display some signs of agglomerations, the spreading behavior in the printing system was improved when compared to the as-received powder. The flowability of the powder was determined to have improved after the heating cycle since the extra layers of powder were not necessary to obtain a uniform layer of powder. For this reason, it was determined that in order to reuse the powder, and remove any excess of binder and agglomerations, a heating cycle was implemented prior to each fabrication. Thermal gravimetric analysis (TGA), as shown in Figure 2, was performed on the fabricated samples prior to sintering to determine the debinding temperature (necessary to remove the binder used during fabrication; the process is explained in detail below). BTO spherical powder shows a pronounced change in mass at a temperature range between $375-425^{\circ} \mathrm{C}$. TGA analysis demonstrates that the last change in mass occurred at $450^{\circ} \mathrm{C}$ for BTO, although the temperature was elevated to $1000^{\circ} \mathrm{C}$ and held for one hour to ensure binder removal since specimen size for TGA analysis was relatively small compared to the powder batch heated. Powder heating also helped improve the powder flowability (the amount of time per layers required for the powder to spread on the powder bed) for powder recycling purposes. 


\subsection{Fabrication and cleaning}

Fabrication was achieved by the binder jetting process using the ExOne M-Lab system. The process consists of the layered manufacturing of three-dimensional parts (previously designed by computer-aided design (CAD) and uploaded in the system as an .stl file) from powder stock material. Powder particles are selectively bonded together in a layer-by-layer fashion. The ExOne M-Lab printer consists of a two-bed system (as shown in Figure 3); one bed is for the base powder material and the other for part fabrication. Powder layers are spread with a stationary roller while the beds are mechanically moving in the $\mathrm{x}$-direction under the roller. Once the powder layer is uniformly spread, the powder bed returns to its original position where binder droplets are selectively deposited through a piezoelectric inkjet print head for part fabrication. After the binder is deposited, the powder bed moves below the heater, where a set amount of time is provided to the layer to allow powder binding of the green body. This is considered as the fabrication of one layer (one full cycle), and the process continues until the 3D part fabrication is complete. When fabrication is finished, the building envelope is placed in the oven at $195^{\circ} \mathrm{C}$ for two hours. This step is performed to cure the binder selectively placed throughout the fabricated part, ultimately allowing the separation of the fabricated geometry from the unbound powder. After the oven curing process, the green body structure is extracted from the bed and sent to the furnace for sintering and binder removal.

For this project, a 2:1 ratio of powder and building deposition was used, which means that the equivalence of two layers of powder from the powder bed (feed) are used to fabricate one layer in the binder deposition bed (build) to achieve better powder packing. This is indicated by the arrow facing down with an $\mathrm{x} 1$ in the build side, and the arrow 
facing up labeled $\times 2$ in the feed side in Figure 3. It was noted that if the ratio was lowered, there was not enough powder to obtain a complete uniform layer necessary to fabricate, therefore, a lower powder packing $(<30 \%)$ was obtained. The method followed to assess powder packing was by setting a total of 100 layer spreads and weighing the powder by assessing its volume (which was dependent on its layer thickness). The input parameters required for fabrication are 1) binder saturation, 2) layer thickness, and 3) powder packing rate. Binder saturation is a computed value used to quantify how much binder is dispensed into each unit volume of powder material. This value is automatically calculated after drop volume and powder packing rate values have been input in the control software. The drop volume measurement is obtained by averaging the weight of five felt pads fired with a calibrated volume of binder; this value is obtained prior to each fabrication process. The powder packing rate is obtained by calculating a percentage based on the density of the material with the density of the powder in the volume created by an area of $40 \times 60 \mathrm{~mm} x$ the distance in mm of 100 layers (dependent on layer thickness). The binder saturation percentage is a measurement of the theoretical percentage of void space in the print material that is filled with binder. Fabrication of barium titanate was performed using a layer thickness of $30 \mu \mathrm{m}$ since smaller layers would not provide a uniform distribution of the powder due to agglomeration. Binder saturation values are calculated prior to each fabrication while powder packing rate is obtained prior to adjusting the layer thickness of the build. 


\subsection{Characterization}

A high temperature cyclical furnace (1730-12 HTF, CM, USA) was used for all sintering profiles. Sintering profiles were selected based on infiltration profiles for metals provided by ExOne. The sintering profile consisted of holding the temperature at $600^{\circ} \mathrm{C}$ for 20 minutes to allow binder burnout and then increasing the temperatures as shown in Figure 4 with a ramp up rate of $10 \%$ min. After reaching the maximum value, the temperature was decreased at intervals of $100^{\circ} \mathrm{C}$ with dwell times of one hour to provide a slower cooling rate exploring the possibility of increasing the density of the parts. Figure 4 shows a detailed plot of the temperature and time used for each sintering profile. Measurements to assess part shrinkage were obtained using a Mitutoyo Absolute Digimatic caliper that has a resolution of $0.01 \mathrm{~mm}$. Parts were measured after binder curing $\left(195^{\circ} \mathrm{C}\right.$ for 2 hours $)$ and after each sintering profile.

Density values were obtained by following the Archimedes' principle where the density of the object is obtained by dividing the weight of the sintered part by the volume of the displaced fluid when the part is immersed in liquid and this is multiplied by the density of the fluid in consideration. For this project, the fluid used was water. In addition to density measurements, percentage of porosity was obtained by using NI Vision Builder software that executes five steps to determine the percentage of porosity by modifying images into a binary code. These steps consist in 1) selection of images to be analyzed;2) determination of the areas necessary for analysis; 3 ) determination of threshold value was obtained by corroborating the final image to be analyzed with the original image to achieve the precision necessary to convert gray-scale colors to either white or black without losing relevant information from the image; 4) calculation of pixels of interest, and 5) calculation 
of porosity percentage based on pixel count. Figure 5 shows the conversion of an SEM image into a binary image with a threshold of $0 \%$ for the lower value, and $96 \%$ for the upper value. The white color in the image on the right side represents the porosity observed in the original image. SEM analysis (TM-1000, Hitachi, Japan) of the cross sections was performed using an accelerating voltage of $15 \mathrm{kV}$ and no sample preparation was required. XRD analysis was obtained using $\mathrm{Cu} \mathrm{k}_{\alpha}$ radiation (D8, Bruker, Germany).

Dielectric constant measurements for the BTO samples were obtained with a vector network analyzer (PNA-X Analyzer, Agilent Technologies, IL, USA) with a frequency capability of $10 \mathrm{MHz}$ to $50 \mathrm{GHz}$. To obtain dielectric constant values for a frequency range of 12.4 to $18 \mathrm{GHz}$, samples of $15.8 \mathrm{~mm}$ in length, $7.9 \mathrm{~mm}$ in height and $5.08 \mathrm{~mm}$ in width were fabricated to use in a $K_{u}$ band waveguide for the specimens. For this reason, percent shrinkage was taken into account to accommodate size dimensions during fabrication. In addition, $\mathrm{CAD}$ files were scaled with $\pm 1 \%$ error to accommodate for any discrepancies during sintering. Samples fabricated with accommodations for shrinkage did not need additional post processing (e.g. grinding to achieve final dimension). The dielectric loss $(\tan \delta)$ was calculated as

$$
\tan \delta=\frac{\varepsilon^{\prime \prime}}{\varepsilon^{\prime}}
$$

where the real component $\varepsilon^{\prime}$ is the dielectric constant and the imaginary component $\varepsilon^{\prime \prime}$ describes the dissipation of the electric field [23].

Dielectric constant values were obtained at different temperatures using an LCR meter (HP $4284 \mathrm{~A})$ at a frequency of $1 \mathrm{kHz}$. After sintering the fabricated parts, electrodes 
were prepared by using silver paint on the top and bottom surfaces of the pellets to build a parallel plate capacitor. The capacitance and the dielectric loss of the sample were measured and the dielectric constant was calculated using the following equation

$$
\varepsilon_{r}=\frac{C d}{\varepsilon_{0} A}
$$

where $\varepsilon_{\mathrm{r}}$ is the relative dielectric permittivity of the material, $C$ is the measured capacitance, $d$ is the distance separating the electrodes, $\varepsilon_{0}$ is the permittivity of vacuum and $A$ is the area of one electrode.

Piezoelectric properties were obtained using an APC YE2730A $\mathrm{d}_{33}$ meter and piezo strain constant $\mathrm{d}_{33}$ values were obtained in $\mathrm{pC} / \mathrm{N}$. In order to do the testing, each specimen was initially poled by placing them in a silicon oil bath between two electrodes, and raising the temperature above $120^{\circ} \mathrm{C}$; then, an electric field of $2 \mathrm{kV} / \mathrm{cm}$ was applied for two hours with the aid of an Acopian P030HP2 high voltage power supply. Subsequently, the sample was allowed to cool down while still applying the electric field. Once the specimen reached ambient temperature $\left(25^{\circ} \mathrm{C}\right)$, the voltage was turned off [24] [25].

\subsection{Results and discussion}

\subsection{Characterization}

Sintering of BTO fabricated specimens was implemented by heating the specimens at 1260,1330 and $1400^{\circ} \mathrm{C}$ for four hours at different binder saturations (Table 1). 
Fabrication for barium titanate with different binder saturations helped determine the minimum percentage that provided a complete part with maximum density (the geometry was not destroyed after binder curing). Powder flow could be assessed by rolling the layers in the feed side of the envelope by counting how many layers were deposited until a complete cover of the tray was obtained. Fabricated and sintered samples of BTO were fragile and dimensional accuracy was not as desired since corners showed rounded edges and overall the specimen provided a granular finish. From the density measurements obtained, shown in Table 1, the maximum density was determined to be obtained when fabricating with a binder saturation of $60 \%$ and a sintering temperature of $1400^{\circ} \mathrm{C}$. Density measurements for binder saturations below $60 \%$ could not be tested due to parts not retaining the desired geometry after curing the binder. Since the geometrical features were similar for CAD and build, further fabrication was completed with $60 \%$ binder saturation for three main reasons: 1) parts were denser, 2) geometrical features were not lost, and 3) binder use was minimized for sustainability purposes.

Sintering is accompanied by non-uniform dimensional changes such as the reduction of axial dimensions known as shrinkage anisotropy [26]. Dimensional shrinkage was higher for specimens sintered at higher temperatures and the percentage varied depending on the fabrication axis. Minimum shrinkage was obtained when sintering at $1260^{\circ} \mathrm{C}$ for the three orientations ( $\mathrm{x}, \mathrm{y}$ and $\mathrm{z}$ axis). Shrinkage in the $\mathrm{z}$-direction was higher for specimens sintered at $1400^{\circ} \mathrm{C}$ where $29.45 \%$ was measured. Shrinkage of $27.67 \%$ was observed for specimens sintered at $1330^{\circ} \mathrm{C}$, and $20.12 \%$ for specimens sintered at $1260^{\circ} \mathrm{C}$. Shrinkage in the x-direction was calculated as $20.83 \%$ for the specimen sintered at $1300^{\circ} \mathrm{C}$, $25.09 \%$ for the specimen sintered at $1330^{\circ} \mathrm{C}$ and $25.62 \%$ for the specimen sintered at 
$1400^{\circ} \mathrm{C}$. In the $\mathrm{y}$-axis, specimens sintered at $1300^{\circ} \mathrm{C}$ had a shrinkage of $20.39 \%$, specimens sintered at $1330^{\circ} \mathrm{C}$ had a shrinkage of $24.05 \%$, and specimens sintered at $1400^{\circ} \mathrm{C}$ had a shrinkage of $24.64 \%$. Details of shrinkage percentage can be observed in Figure 6.

Figure 7 shows a magnified set of images obtained from a BTO cube specimen fabricated by binder jetting technology with the minimum amount of binder $(60 \%)$ that provides dimensional geometry similar to the CAD file. The specimen was exposed to a temperature of $1200^{\circ} \mathrm{C}$ for four hours. After the specimen was treated to this temperature it was too fragile to perform density measurements. Figure 7a shows the path followed by the deposition of the binder droplets during fabrication, and Figure $7 \mathrm{~b}$ and $7 \mathrm{c}$ show magnified images of the voids left behind in the sample due to binder burnout, which - based on the TGA results - occurs at a maximum temperature of $500^{\circ} \mathrm{C}$. Binder voids show a doubleoverlapping-circle morphology for each individual drop. Binder drops are $60 \mu \mathrm{m}$ in length and $20 \mu \mathrm{m}$ in width, the spacing between each drop in the same column is approximately 30 $\mu \mathrm{m}$, while the distance between columns varies due to powder agglomeration at multiple locations throughout the specimen. These images show that sintering has to occur by grain growth for the material to overcome the empty spaces left behind after binder burnout, and close any gaps around the grains in order to obtain denser parts. Furthermore, additional research on sintering profiles could explore if longer dwell times at lower temperatures provide denser parts while eliminating grain growth.

Figure 8 shows low and high magnification SEM images of the specimens when sintered at $1260^{\circ} \mathrm{C}(\mathrm{a}$ and $\mathrm{b}), 1330^{\circ} \mathrm{C}\left(\mathrm{c}\right.$ and d), and $1400^{\circ} \mathrm{C}(\mathrm{e}$ and $\mathrm{f})$. Figure $8 \mathrm{a}$ and b show the agglomeration of powder and the lack of sintering in the specimen. As shown in Figure $8 \mathrm{~b}$ agglomerated powder is possibly held in place by surface diffusion at random locations 
as can be observed by the agglomerate. For this specimen and specimens sintered at higher temperatures, the binder path, as observed in Figure 7, was not apparent. Sintering at $1260^{\circ} \mathrm{C}$ is not recommended for BTO specimens fabricated by binder jetting since no indications of sintering are observed, and average grain size was $91 \mu \mathrm{m}$. Specimen appearance can be described as granular and fragile for the fabricated specimens. Figure 8c and d show images corresponding to specimens sintered at $1330^{\circ} \mathrm{C}$. Samples show irregular grain growth, where small grains are observed surrounding larger grains, indicating that sintering was still in progress. Void spaces are also irregular and interconnected at various dimensional planes, and space between grown grains is also observed. An average grain size of $21 \mu \mathrm{m}$ was measured for specimens sintered at $1330^{\circ} \mathrm{C}$. Figure $8 \mathrm{e}$ and $\mathrm{f}$ show representative images of specimens sintered at $1400^{\circ} \mathrm{C}$; specimens show uniform grain growth where an average grain size of $44 \mu \mathrm{m}$. Figure $8 \mathrm{e}$ shows similar aspects as the specimen sintered at $1330^{\circ} \mathrm{C}$ where a uniform smaller grain size range is observed throughout the specimen. In addition, the presence of voids and interconnected porosity continues to persist at the increased temperature of $1400^{\circ} \mathrm{C}$. Specimens for both sintering temperatures $\left(1330\right.$ and $\left.1400^{\circ} \mathrm{C}\right)$ are sturdier and surface finish is less granular.

Densities obtained for BTO sintered at different temperatures are provided in Table 2. Densities were best for sintering temperature at $1400^{\circ} \mathrm{C}$ for BTO when sintered for four hours, which correlates with the SEM images of each specimen. Table 2 also lists the amount of porosity calculated by the NI Vision software for specimens sintered at 1260 , 1330 and $1400^{\circ} \mathrm{C}$. Porosity obtained is relatively consistent and opposite with the trend observed for the sintering temperature and density, as expected. For density values, as the temperature was increased, the density calculated was increased; for porosity values, as 
sintering temperature increased, porosity was decreased. Obtained values for porosity cannot be considered representative of each specimen since each value was obtained from an average of eight pictures at magnifications higher than 100X. Porosity measurements obtained from two-dimensional images to interpret three-dimensional parts were only used to corroborate the density-trend obtained from the Archimedes' principle method as the imaging technique is not comprehensive across the full volume.

Densification during sintering can occur mainly from two types of mechanisms: lattice diffusion and grain boundary diffusion, where grain boundaries are the material source for both mechanisms. Samples sintered at $1330^{\circ} \mathrm{C}$ show more empty spaces in between the grains throughout the specimen when compared to samples sintered at $1400^{\circ} \mathrm{C}$, which decreases the density of the sintered specimens, in addition to the presence of interconnected voids though the sample. Solid-state sintering usually occurs in three stages, which are: i) initial: involving necking and grain growth, ii) intermediate: resulting in shrinkage and densification, and iii) final: elimination of close pores and formation of dense microstructure [27]. The specimens analyzed lead to the conclusion that only the intermediate stage of sintering was observed in the BTO parts fabricated with binder jetting. In these specimens, localized grain growth occurred regardless of the shrinkage observed and there was a lack of necking from grain to grain. Shrinkage in BTO parts fabricated by the binder jetting technology is occurring due to the reduction of voids left by the binder that have been burned out (Figure 7) and not because of the completion of the sintering process. For the analyzed BTO specimens, shrinkage at $1260^{\circ} \mathrm{C}$ occurred by $\sim 21 \%$ in all build directions ( $\mathrm{x}-, \mathrm{y}-$ and $\mathrm{z}$-axis) as previously mentioned, and higher shrinkage was observed as the sintering temperature was increased (Figure 6). 


\section{$3.2 X$-ray diffraction analysis}

Transition temperatures for BTO from tetragonal crystal structure to cubic occurs at $130^{\circ} \mathrm{C}$ while transformation from cubic to hexagonal occurs at $1460^{\circ} \mathrm{C}$. When cooling through the Curie point $\left(\sim 120^{\circ} \mathrm{C}\right)$, a stress-related transformation occurs to obtain the tetragonal phase, which can be minimized if the grain dimensional change is minimized [6]. For sensor applications, a hexagonal crystal structure is not desired since its properties are no longer ferroelectric, while tetragonal structures are both polar and ferroelectric [27]. XRD analysis results showed how the BTO powder obtained is mainly tetragonal with the presence of cubic phase (Figure 9). These two structures, cubic and tetragonal, remain present when sintered at 1260,1330 , and $1400^{\circ} \mathrm{C}$. After a sintering cycle at $1400^{\circ} \mathrm{C}$ for four hours, a hexagonal peak in the 103 direction at $2 \theta=43.2^{\circ}$ is observed. In addition, when sintering at this temperature, the presence of two extra lines occur, at $2 \theta=42.1$ and $2 \theta=49.5$ which are not identified.

\subsection{Dielectric constant}

Dielectric constant measurements for BTO ranged from 8.62 to 6.23 for a frequency range of 12.4 to $18 \mathrm{GHz}$, respectively, for the specimen sintered at $1260^{\circ} \mathrm{C}$. Dielectric constant values of 6.95 to 4.09 , for the same frequency range, were obtained for specimens sintered at $1330^{\circ} \mathrm{C}$. Dielectric loss was also lower for specimens sintered at $1330^{\circ} \mathrm{C}$, both the dielectric constant and the loss obtained for BTO sintered at 1260 and $1330^{\circ} \mathrm{C}$ can be observed in Figure 10a and b, respectively. Low dielectric constant $(\varepsilon)$, low dielectric loss factor and high dielectric tenability are some of the desired characteristics for dielectric 
materials for phased-array applications [28]. Figure 11 shows the dielectric constant and the dielectric loss when measured at a frequency of $1 \mathrm{kHz}$ at different temperatures. As sintering temperature was increased, the dielectric constant increased. Previous work has demonstrated that the dielectric constant values decrease as the grain size increases for $\mathrm{BaTiO}_{3}$ [29]. With further research, grain size and porosity can be improved when fabricated by binder jetting and the dielectric constant can be increased for ultracapacitors or 3D antenna structures applications. Nonetheless, it was noted that the dielectric values obtained are dependent of frequency regardless of sintering temperature and part density. In order to understand this phenomena better, further testing should be necessary to corroborate parts polarization and specimen size to frequency and dielectric constant for BTO specimens fabricated by binder jetting technology.

\subsection{Piezoelectric characteristics}

Piezoelectric properties exhibited by $\mathrm{BaTiO}_{3}$ fabricated by binder jetting technologies exhibited a piezoelectric coefficient $\mathrm{d}_{33}$ that improved with higher sintering temperatures with 74.1 for specimens sintered at $1400^{\circ} \mathrm{C}, 41.73$ at $1330^{\circ} \mathrm{C}$, and $13.23 \mathrm{pC} / \mathrm{N}$ at $1260^{\circ} \mathrm{C}$, possibly due to improvements in density and reduced grain size. Values for BTO when sintered at $1180^{\circ} \mathrm{C}$ have reached $69 \mathrm{pC} / \mathrm{N}$ [30]. The values obtained for the many characteristics of interest (dielectric constant, dielectric loss and the piezoelectric coefficient $\mathrm{d}_{33}$ ) all are expected to improve with an increase in specimens' density and a decrease in grain size and further research is required to explore other possible parameters such as sintering time, powder morphology, layer thickness, further sintering temperatures and binder chemistries. 


\subsection{Conclusions}

Piezoelectric barium titanate is considered an ideal candidate for sensor applications that can be used in power plants, gas turbines, and oxy-fuel combustion, due to the ability to monitor pressure. Fabrication of pressure sensors by additive manufacturing through binder jetting technology has proven to be a promising method, which can provide arbitrarily-formed, complex geometries of energy-harvesting structures. The design freedom of 3D printing can also lead to application in complex ultracapacitors. However, research is still required to increase the density of the fabricated parts after sintering. Several methods can be pursued for this purpose (e.g. double stage sintering, isostatic pressing, sintering duration, etc). Cold isostatic pressing holds promise as well as long as no closed internal thin walls are present in the design. When sintering BTO specimens fabricated by binder jetting, special attention is required to assess a shrinking factor in the design in relation with the sintering temperature. A maximum theoretical density of $65 \%$ was obtained when sintering at $1400^{\circ} \mathrm{C}$ for four hours. It is foreseen that denser parts and smaller grain sizes could enhance the values obtained for the dielectric constant at all sintering temperatures, and the piezoelectric properties $\left(\mathrm{d}_{33}\right)$ of BTO fabricated by binder jetting.

\subsection{Acknowledgements}

The research presented here was performed at The University of Texas at El Paso (UTEP) within the W. M. Keck Center for 3D Innovation (Keck Center), providing access to state- 
of-the-art facilities and equipment as a result of funding from the State of Texas Emerging Technology Fund. We are also grateful to DOE NETL SC-13-389 for funding this project. Special thanks to Satya K. Gullapalli, Jose Avila, Ubaldo Robles and Maria Yañez for assisting in various aspects of this project.

\subsection{References}

[1] C. B. Carter and M. G. Norton, Ceramic Materials; Science and Engineering, New York: Springer, 2007.

[2] V. Buscaglia, M. Viviani, M. T. Buscaglia, P. Nanni, L. Mitoseriu, A. Testino, E. Stytsenko, M. Daglish, Z. Zhao and M. Nygren, "Nanostructured barium titanate ceramics," Powder Technology 148, pp. 24-27, 2004.

[3] W. Maison, S. Ananta, T. Tunkasiri, P. Thavornyutikarn and S. Phanichphant, "Effect of Calcination Temperature on Phase Transformation and Particle size of Barium Titanate Fine Powders Synthesized by the Catecholate Process," ScienceAsia 27, pp. 239-243, 2001.

[4] S. Chatterjee, B. D. Stojanovic and H. S. Maiti, "Effect of additives and powder preparation techniques on PTCR properties of barium titanate," Materials Chemistry and Physics 78, pp. 702-710, 2003.

[5] T. Sahoo, S. K. Tripathy, M. Mohapatra, S. Anand and R. P. Das, "X-ray diffraction and microstructural studies on hydrothermally synthesized cubic barium titanate from 
TiO2-Ba(OH)2-H20 system," Materials Letters 61, pp. 1323-1327, 2007.

[6] J. H. Chen, B. H. Hwang, T. C. Hsu and H. Y. Lu, "Domain switching of barium titanate ceramics induced by surface grinding," Materials Chemistry and Physics 91, pp. 67-72, 2005.

[7] S. Ducharme, "An Inside-Out Approach to Storing Electrostatic Energy," Perspective, pp. 2447-2450, 2009.

[8] O. Harizanov, A. Harizanova and T. Ivanova, "Formation and characterization of solgel barium titanate," Materials Science and Engineering B106, pp. 191-195, 2004.

[9] W. L. Suchanek and M. Yoshimura, "Preparation of Strontium Titanate Thin Films by the Hydrothermal-Electrochemical Method in a Solution Flow System," J. Am. Ceram. Soc, pp. 2864-2868, 1998.

[10] C. Herard, A. Faivre and J. Lemaitre, "Surface Decontamination Treatments of Undoped BaTiO3-Part II: Influence on Sintering," Journal of the European Ceramic Society, pp. 145-153, 1995.

[11] Q. R. Marksteiner, G. King, T. A. Wynn, M. B. Treiman, D. A. Dalmas, A. Llobet, W. B. Haynes, D. R. Guidry and P. A. Papin, "Slip casting of sol-gel-synthesized barium strontium zirconium titanate ceramics," Materials Science, pp. 5788-5800, 2013.

[12] Pall Corporation, "Ceramic Slip-Barium Titanate Slurry for Multilayer Ceramic Capacitor Manufacturing," 2014. [Online]. Available: http://www.pall.com/main/microelectronics/ceramic-slip-barium-titanate-slurry-for54526.page. [Accessed 2014]. 
[13] H. M. Nur, Fabrication of advanced ceramics and selective metallization of nonconductive substrates by inkjet printing, Brunel University, 2002.

[14] UC San Diego, "3D Fabrication of Piezoelectric Polymer Composite Materials". USA Patent Tech ID: 24418/ UC Case 2014-159-0, 2014.

[15] K. Kim, W. Zhu, X. Qu, c. Aaronson, W. R. McCall, S. Chen and D. J. Sirbuly, "3D Optical Printing of Piezoelectric Nanoparticle-Polymer Composite Materials," ACS Nano, 2014.

[16] J. H. Jang, S. Wang, S. M. Pilgrim and W. A. Schulze, "Preparation and Characterization of Barium Titanate Suspensions for Stereolithography," J. Am. Ceram. Soc, pp. 1804-1806, 2000.

[17] L. J. Gao, X. L. Liu, J. Q. Zhang, S. Q. Wang and J. F. Chen, "Grain-controlled barium titanate ceramics prepared from high-gravity reactive precipitation process powder," Materials Chemistry and Physics 88, pp. 27-31, 2004.

[18] B. Ertug, T. Boyraz and O. Addemir, "Humidity sensing properties of lanthanum doped barium titanate ionic conductive ceramic sensor," in 5th International Powder Metallurgy Conference, Ankara Turkiye, 2008.

[19] W. Sun, D. J. Dcosta, F. Lin and T. El-Raghy, "Freeform fabrication of Ti3SiC2 powder-based structures Part I-Integrated fabrication process," Materials Processing Technology, pp. 343-351, 2002.

[20] C. Gomez-Yañez, C. Benitez and H. Balmori-Ramirez, "Mechanical activation of the synthesis reaction of $\mathrm{BaTiO} 3$ from a mixture of $\mathrm{BaCO} 3$ and $\mathrm{TiO} 2$ powders," Ceramics 
International, pp. 271-277, 2000.

[21] J. Schindall, "The charge of the ultracapacitors," IEEE Spectrum, pp. 42-46, 2007.

[22] R. C. Smith, Smart Material Systems Model Development, Philadelphia, PA: Society for Industrial and Applied Mathematics, 2005.

[23] S. J. Penn, N. M. Alford, A. Templeton, X. Wang, M. Xu, M. Reece and K. Schrapel, "Effect of Porosity and Grain Size on the Microwave Dielectric Properties of Sintered Alumina," Commnications of the American Ceramic Society, pp. 1885-1888, 1997.

[24] Gulton Industries, Inc, "Polarization of Barium Titanate," 1957.

[25] A. V. Srinivasan and D. M. McFarland, Smart Structures Analysis and Design, NY: Cambridge University Press, 2001.

[26] E. A. Olevsky and R. M. German, "Effect of Gravity on Dimensional Change during Sintering - I. Shrinkage Anisotropy," Acta mater., pp. 1153-1166, 2000.

[27] S. Subramaniam, In situ high temperature environmental scanning electron microscopic investigations of sintering behavior in barium titanate, University of Cincinnati, 2006.

[28] L. Wu, Y. C. Chen, C. Huang, Y. Chou and Y. Tsai, "Direct-Current Field Dependence of Dielectric Properties in Alumina-Doped Barium Strontium Titanate," J. Am. Ceram. Soc.,, pp. 1713-1719, 2000.

[29] M. M. Vijatović, J. D. Bobić and B. D. Stojanović, "History and Challenges of Barium Titanate: Part II," Sience of Sintering, pp. 235-344, 2008.

[30] UCE ultrasonic co., Ltd, "Barium Titanate Piezoelectric Ceramics," 1999-2011. 
[Online]. Available: http://www.ultra-piezo.com/2011/1125/1184.html. [Accessed 2014]. 


\section{Table Captions}

Table 1. Density of $\mathrm{BaTiO}_{3}$ at various binder saturations when fabricated with a layer thickness of $30 \mu \mathrm{m}$

Table 2. Density values obtained for specimens fabricated with $60 \%$ binder saturation 


\section{Figure Captions}

Figure 1. SEM images of a) as-received powder and b) heated powder

Figure 2. TGA analysis for BTO when fabricated using $60 \%$ binder saturation

Figure 3. Schematic of M-Lab system binder jetting technology

Figure 4. Sintering profiles

Figure 5. Example of image analyzed for porosity percentage calculation

Figure 6. Percent shrinkage at different orientations when sintering at 1260, 1330 and $1400^{\circ} \mathrm{C}$

Figure 7. Sequential set of images showing the presence of the voids left from the binder that has been burned out after heating the sample at $1200^{\circ} \mathrm{C}$ for four hours a) low magnification image illustrating the binder path left in BTO specimen, b) and c) magnified images of the areas enclosed in figure a) and b) respectively.

Figure 8. a) and b) low and high magnification of BTO specimen after sintering at $1260^{\circ} \mathrm{C}$ for four hours; c) and d) low and high magnification of BTO specimen after sintering at $1330^{\circ} \mathrm{C}$; e) and f) low and high magnification of BTO specimen sintered at $1400^{\circ} \mathrm{C}$ Figure 9. XRD data for BTO powder and specimens sintered at different temperatures Figure 10. Dielectric constant (a) and dielectric loss (b) for BTO fabricated by binder jetting technology

Figure 11. a) Dielectric constant, and b) dielectric loss for $\mathrm{BaTiO}_{3}$ at $1 \mathrm{KHz}$ at various temperatures 
Table 1. Density of $\mathrm{BaTiO}_{3}$ at various binder saturations when fabricated with a layer thickness of $30 \mu \mathrm{m}$

\begin{tabular}{|c|c|c|}
\hline $\begin{array}{c}\text { Sintering } \\
\text { Temperature } \\
\left({ }^{\mathbf{}} \mathbf{C}\right)\end{array}$ & $\begin{array}{c}\text { Binder } \\
\text { Saturation } \\
(\mathbf{\%})\end{array}$ & $\begin{array}{c}\text { Density } \\
\left(\mathbf{g} / \mathbf{c m}^{\mathbf{3}}\right)\end{array}$ \\
\hline \multirow{3}{*}{$\mathbf{1 2 6 0}$} & 60 & 1.58 \\
\cline { 2 - 3 } & 75 & 1.46 \\
\cline { 2 - 3 } & 120 & 1.48 \\
\hline \multirow{3}{*}{$\mathbf{1 3 3 0}$} & 60 & 1.41 \\
\cline { 2 - 3 } & 75 & 1.39 \\
\cline { 2 - 3 } & 120 & 1.39 \\
\hline \multirow{3}{*}{$\mathbf{1 4 0 0}$} & 60 & 1.37 \\
\cline { 2 - 3 } & 75 & 1.40 \\
\cline { 2 - 3 } & 120 & 1.39 \\
\hline
\end{tabular}


Table 2. Density values obtained for specimens fabricated with $60 \%$ binder saturation

\begin{tabular}{|c|c|c|c|c|}
\hline Material & $\begin{array}{c}\text { Sintering } \\
\text { Temperature }\left({ }^{\circ} \mathrm{C}\right)\end{array}$ & $\begin{array}{l}\text { Sintering } \\
\text { Time (hrs) }\end{array}$ & $\begin{array}{c}\text { Density } \\
\left(\mathrm{g} / \mathrm{cm}^{3}\right) /(\%)\end{array}$ & Porosity (\%) \\
\hline \multirow{3}{*}{ BTO } & 1260 & \multirow{3}{*}{4} & 2.49 / 41.4 & 31 \\
\hline & 1330 & & $3.65 / 60.6$ & 18 \\
\hline & 1400 & & $3.93 / 65.2$ & 7 \\
\hline
\end{tabular}




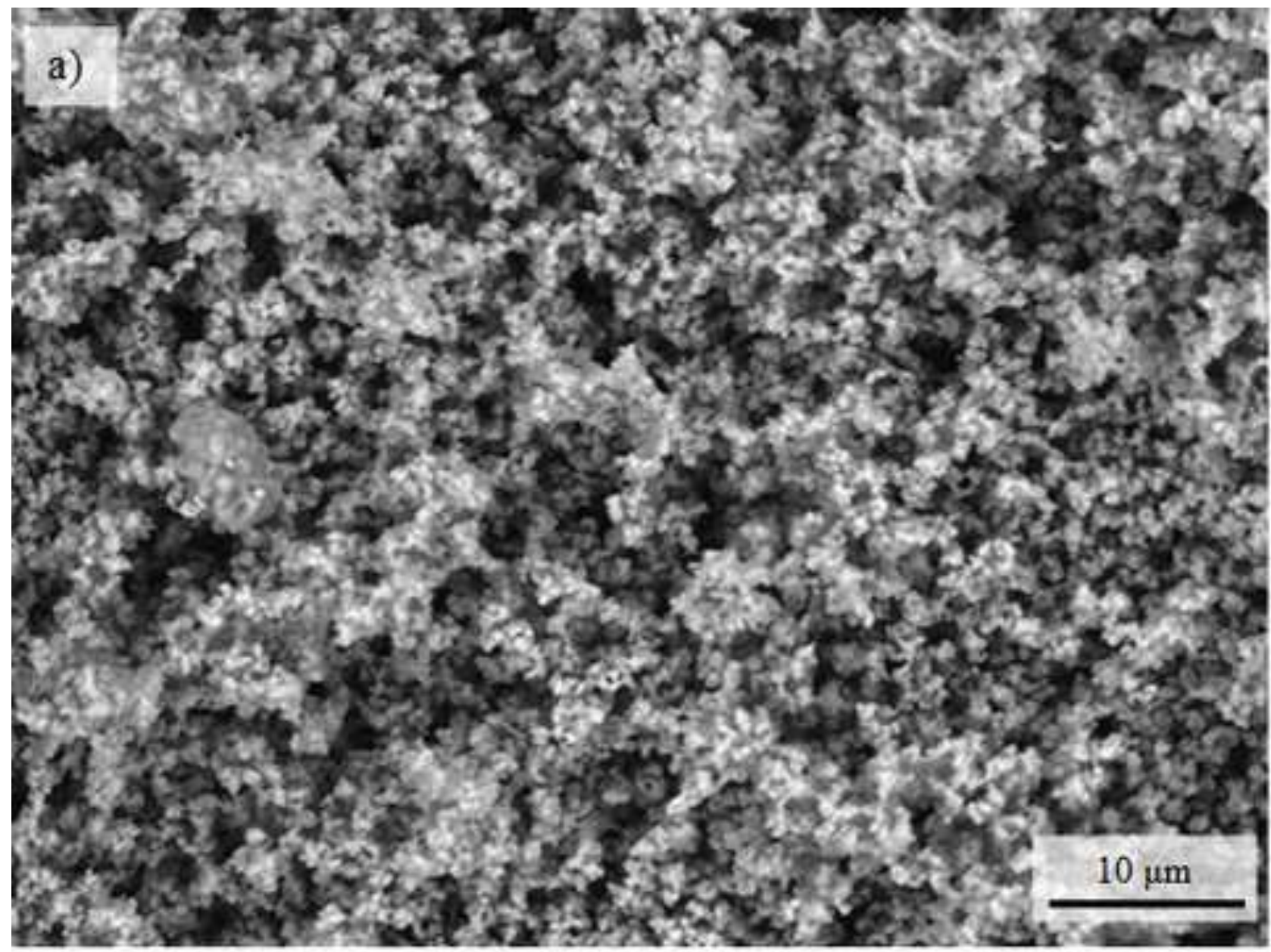

(b)

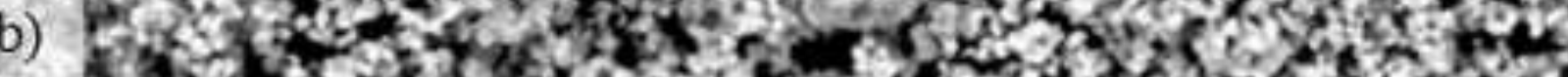

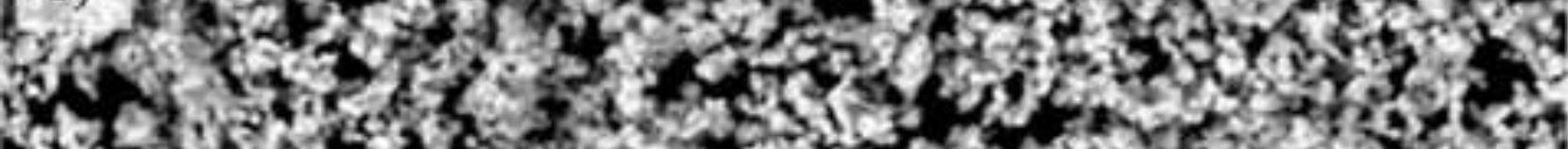

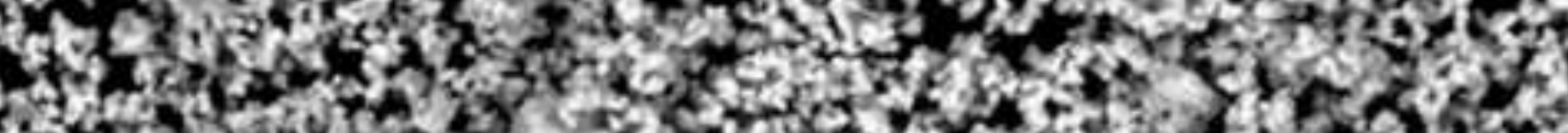

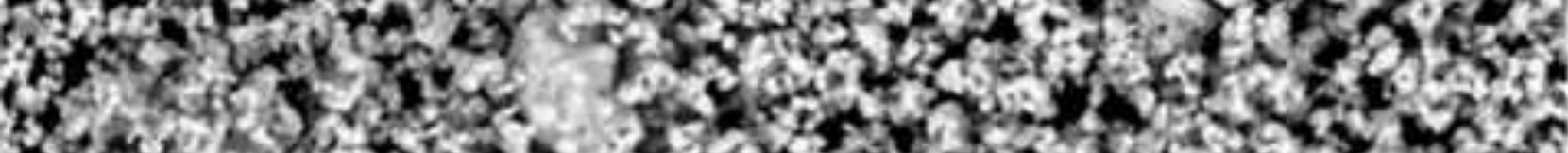

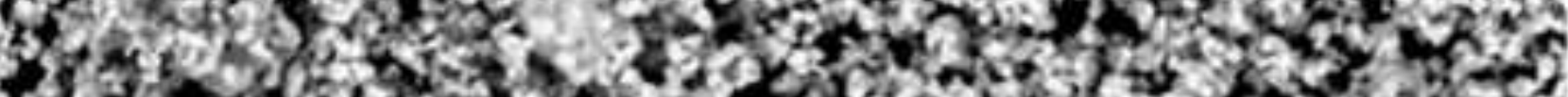

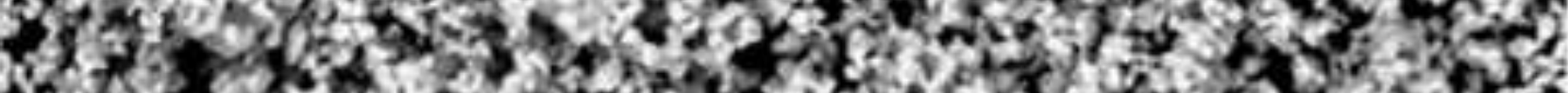

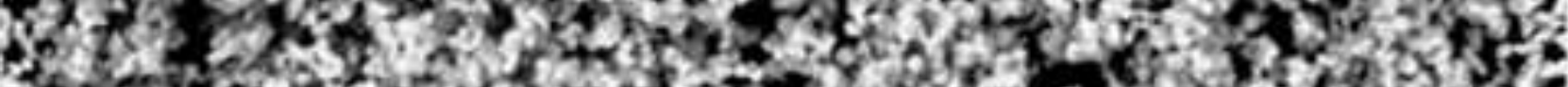

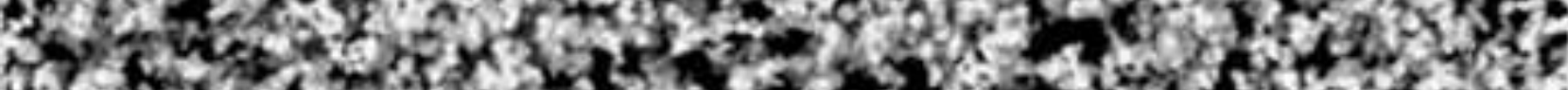

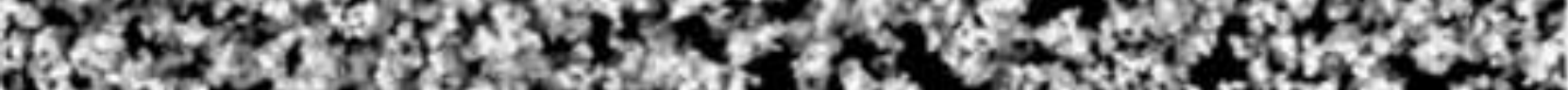
dEs

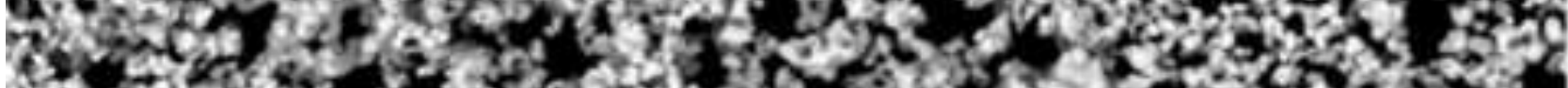

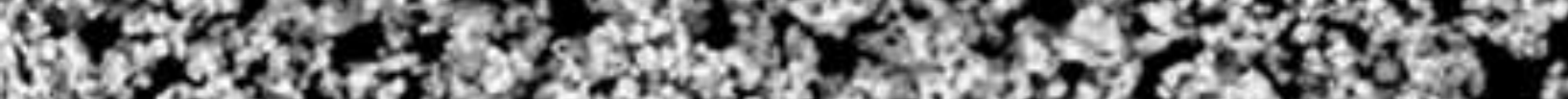

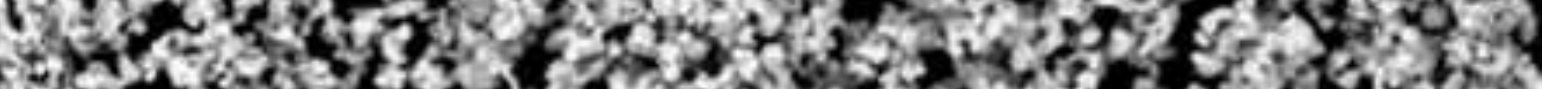

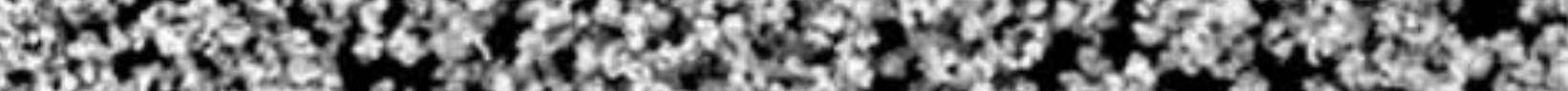
F.

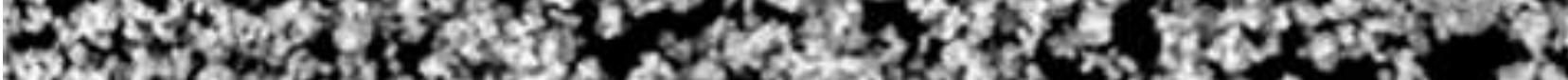

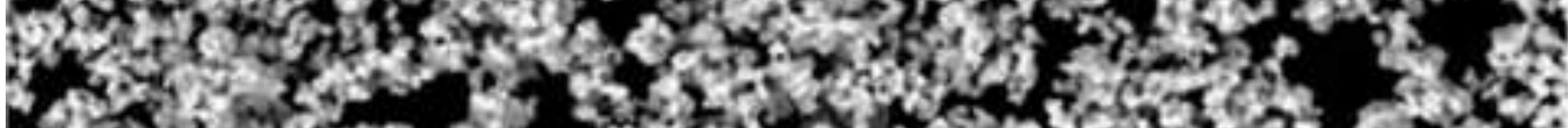

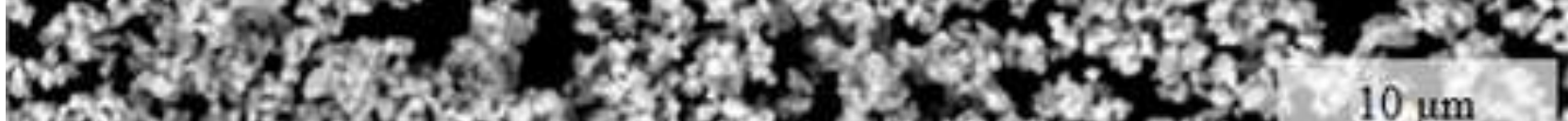

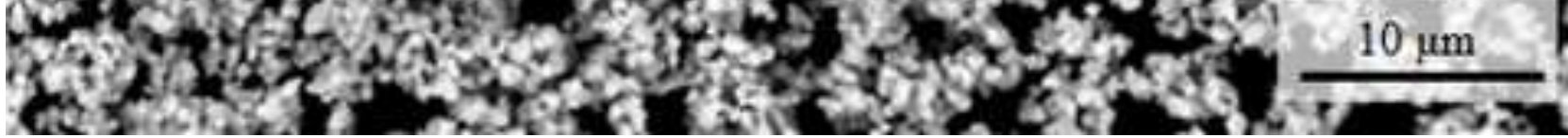


TG $/ \%$

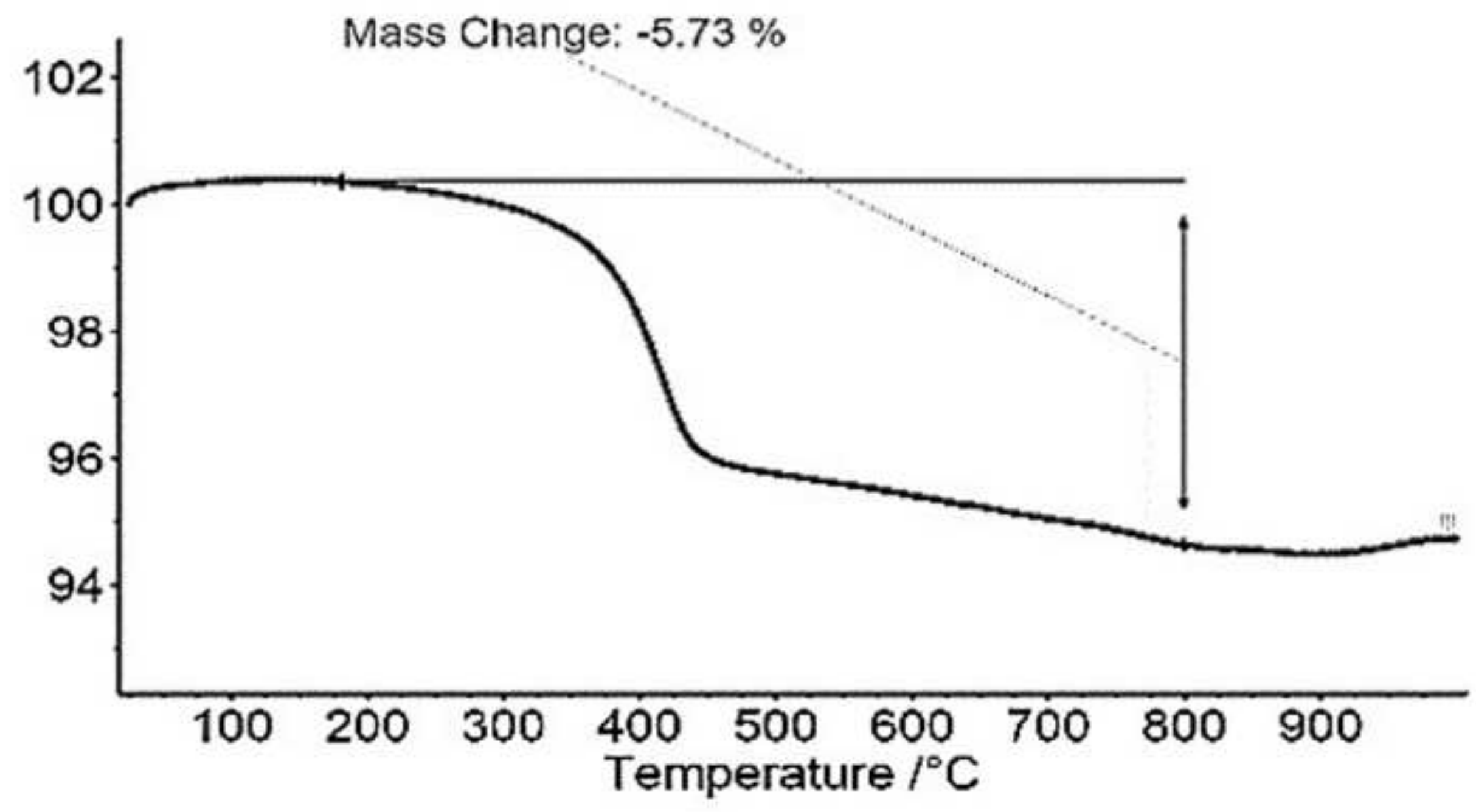


Click here to download high resolution image

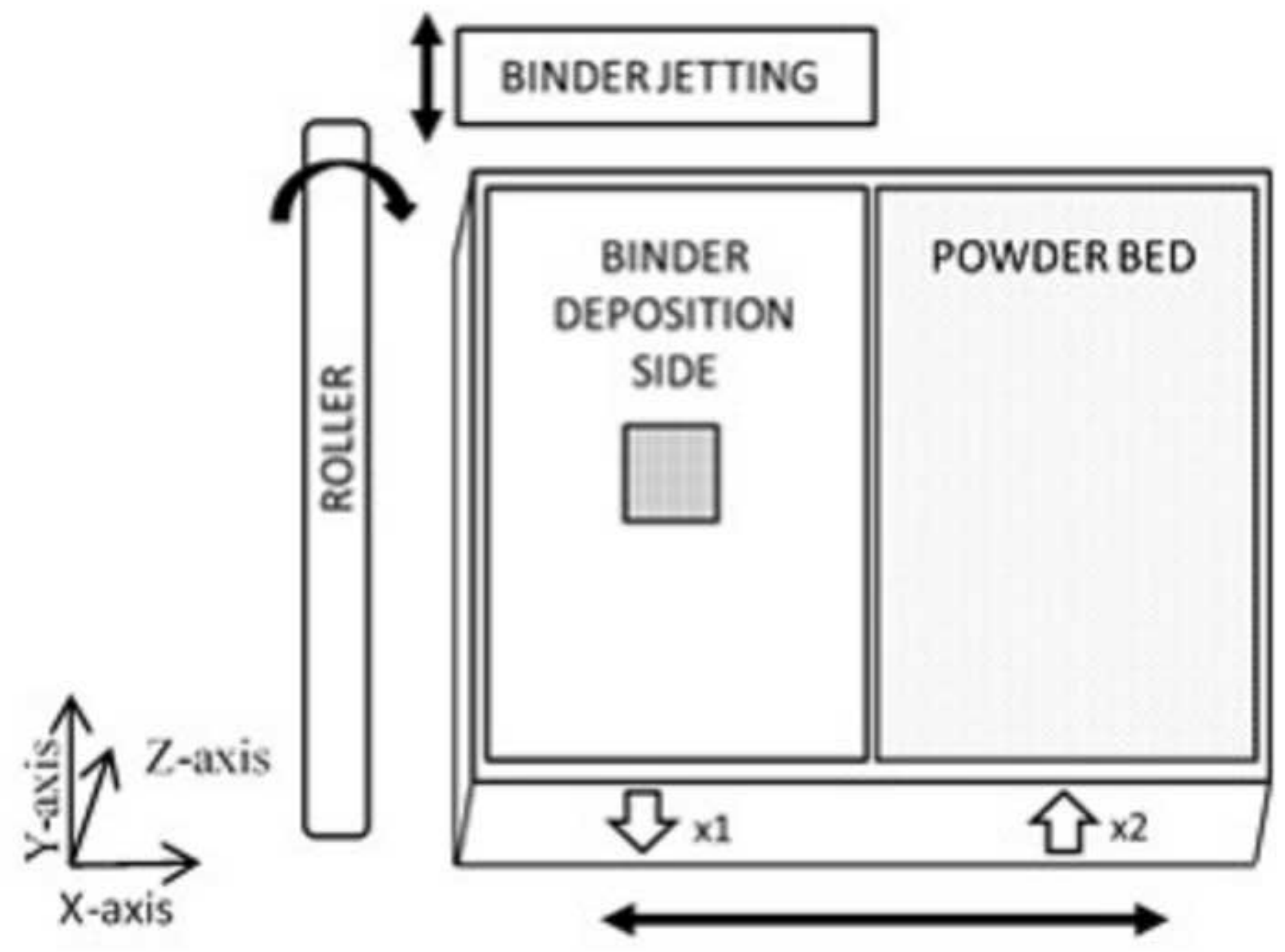




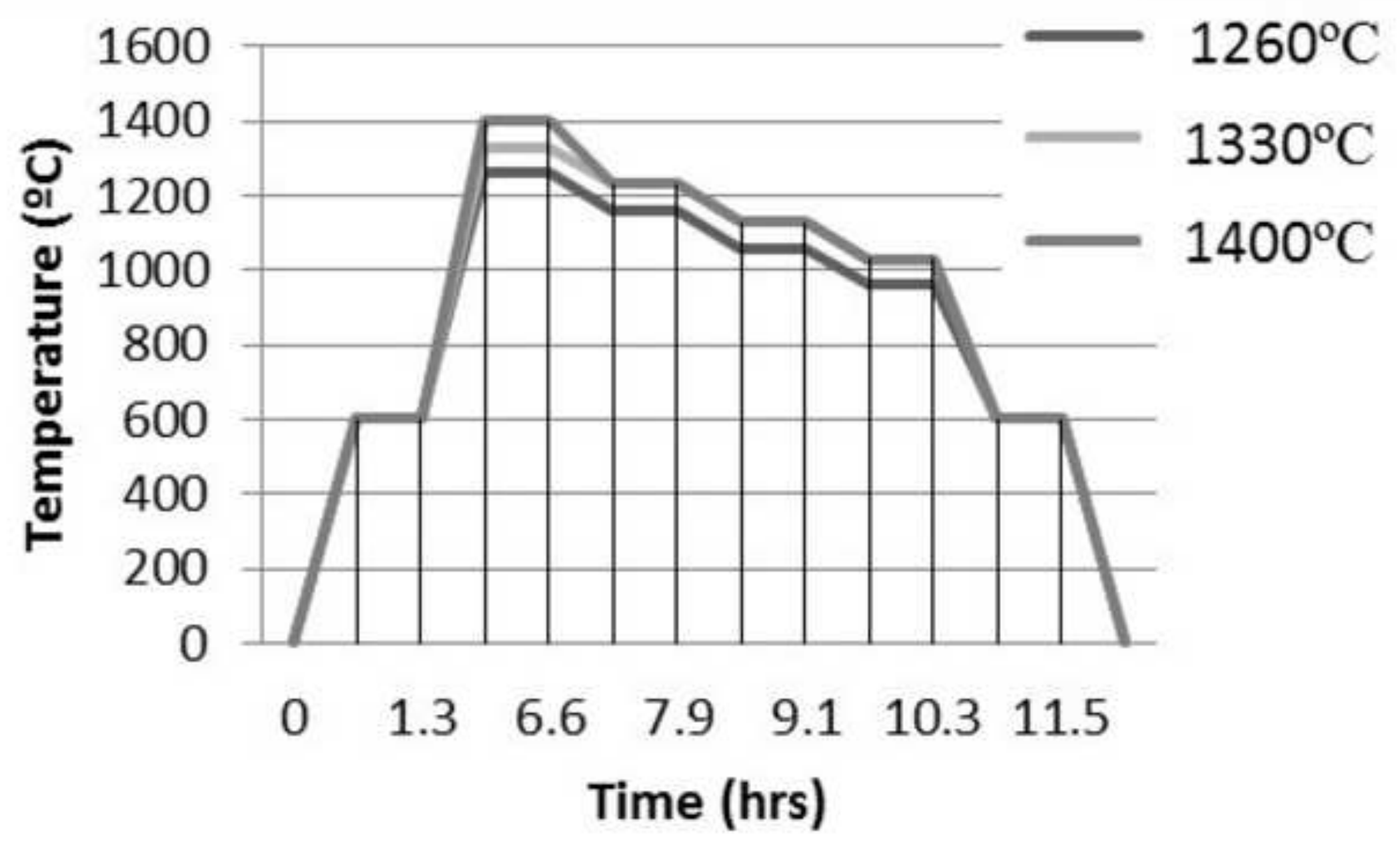



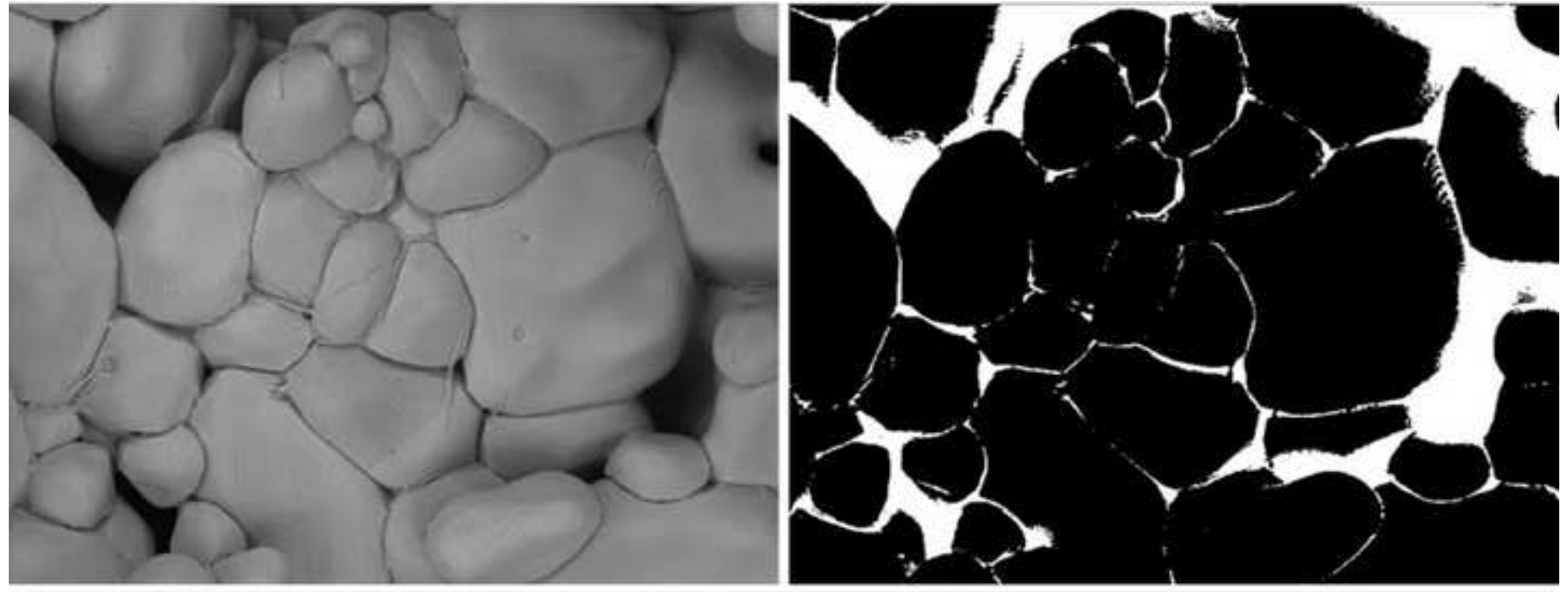

Inspect

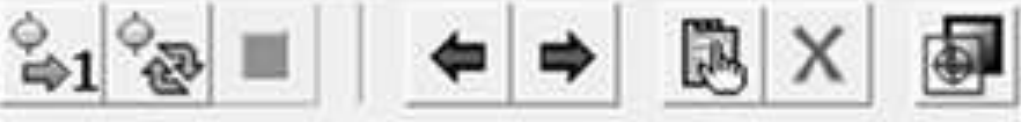

D Display Result Image for this State

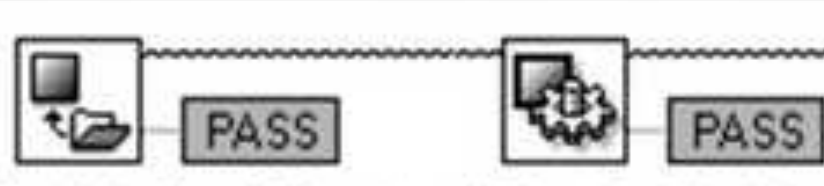

Simulate Acquisition 1 Vision Assistant 1

BaTIO3 1800x A.jpg

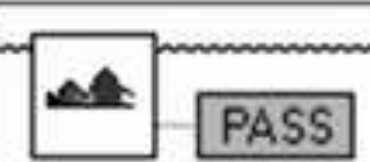

Threshold Image 1

Threshold $=96$

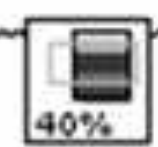

Count Pixels 1

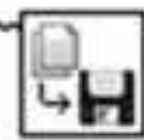

Data Logging 1 
Click here to download high resolution image

\section{Shrinkage after Sintering}

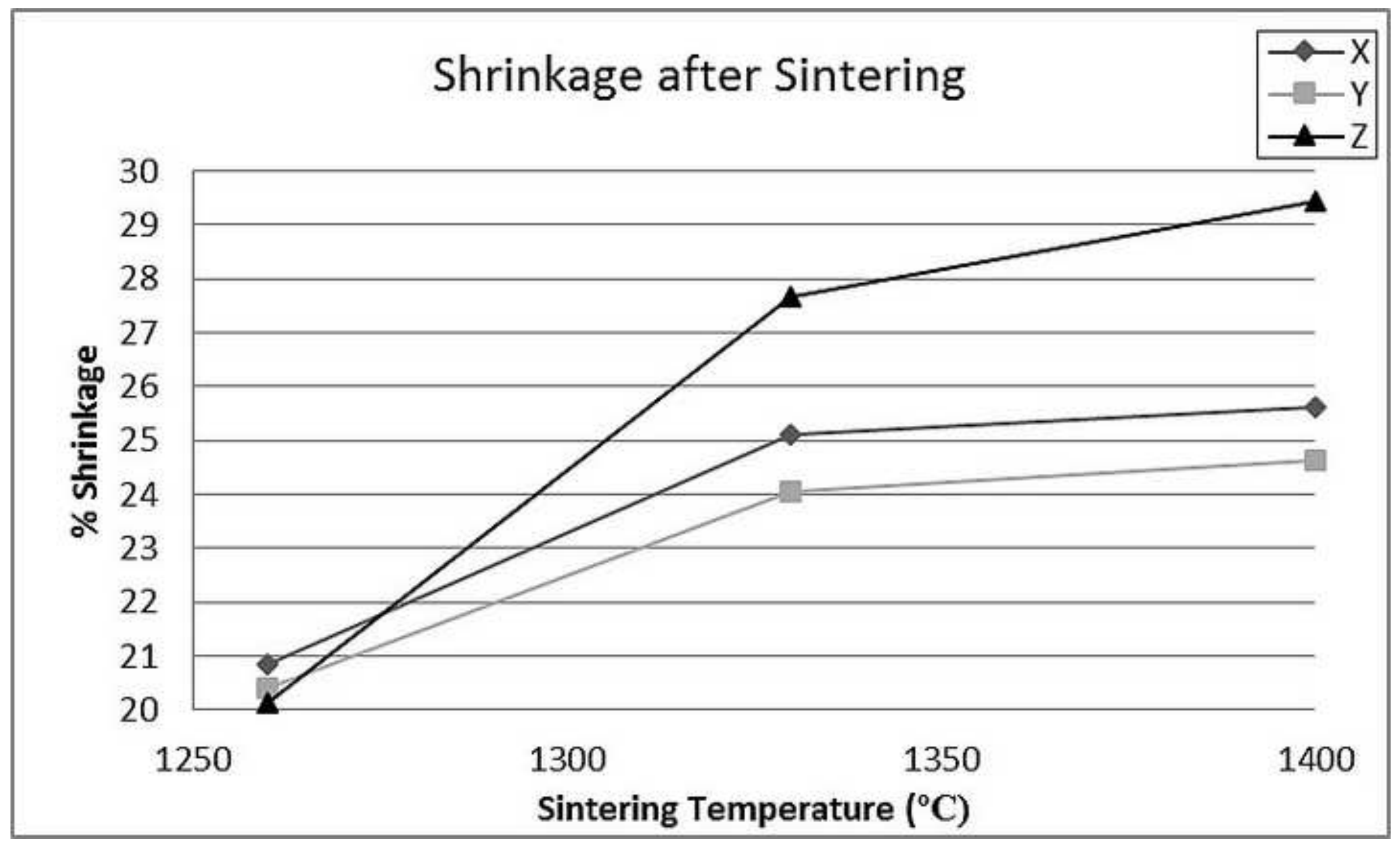


Click here to download high resolution image

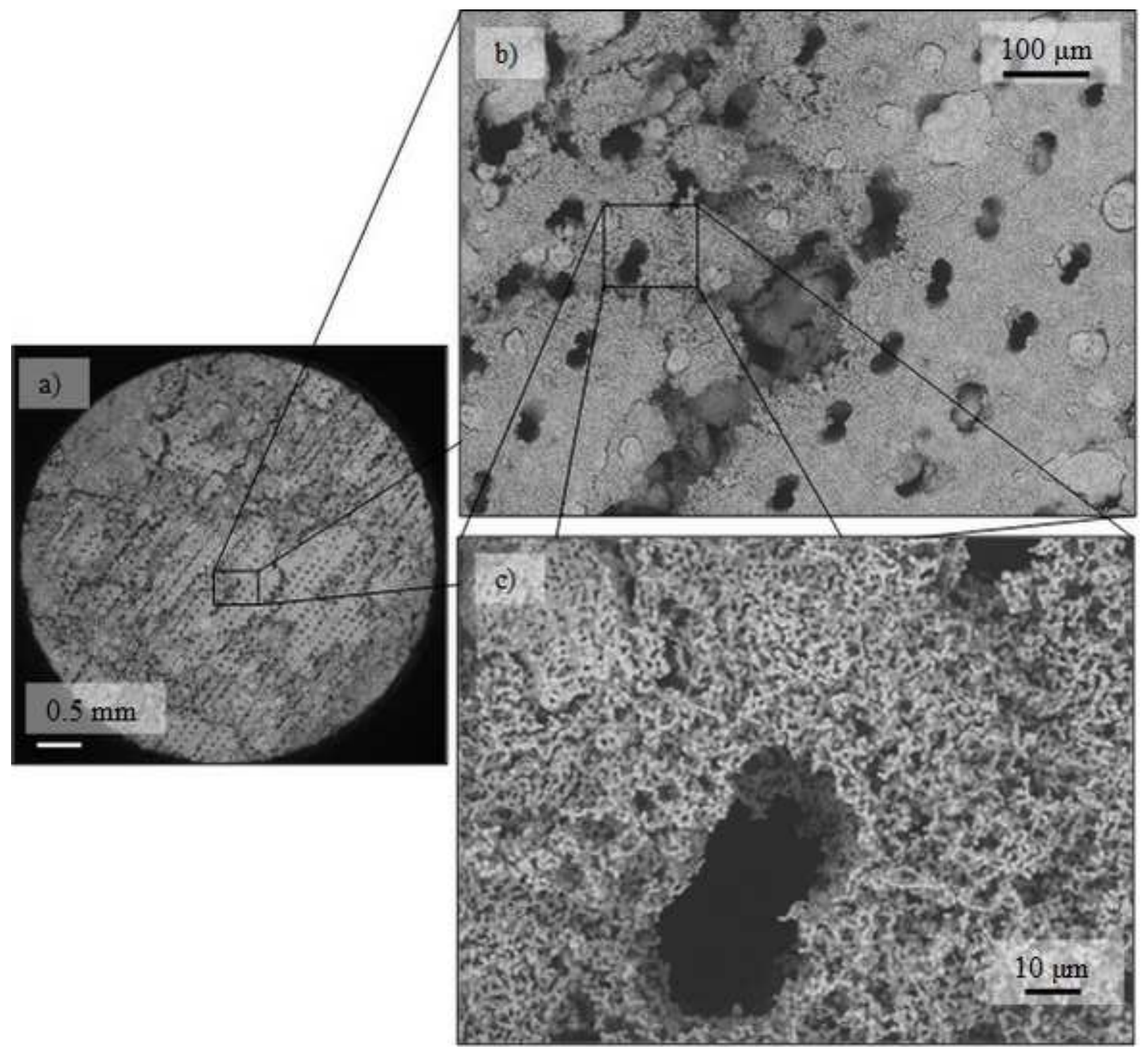



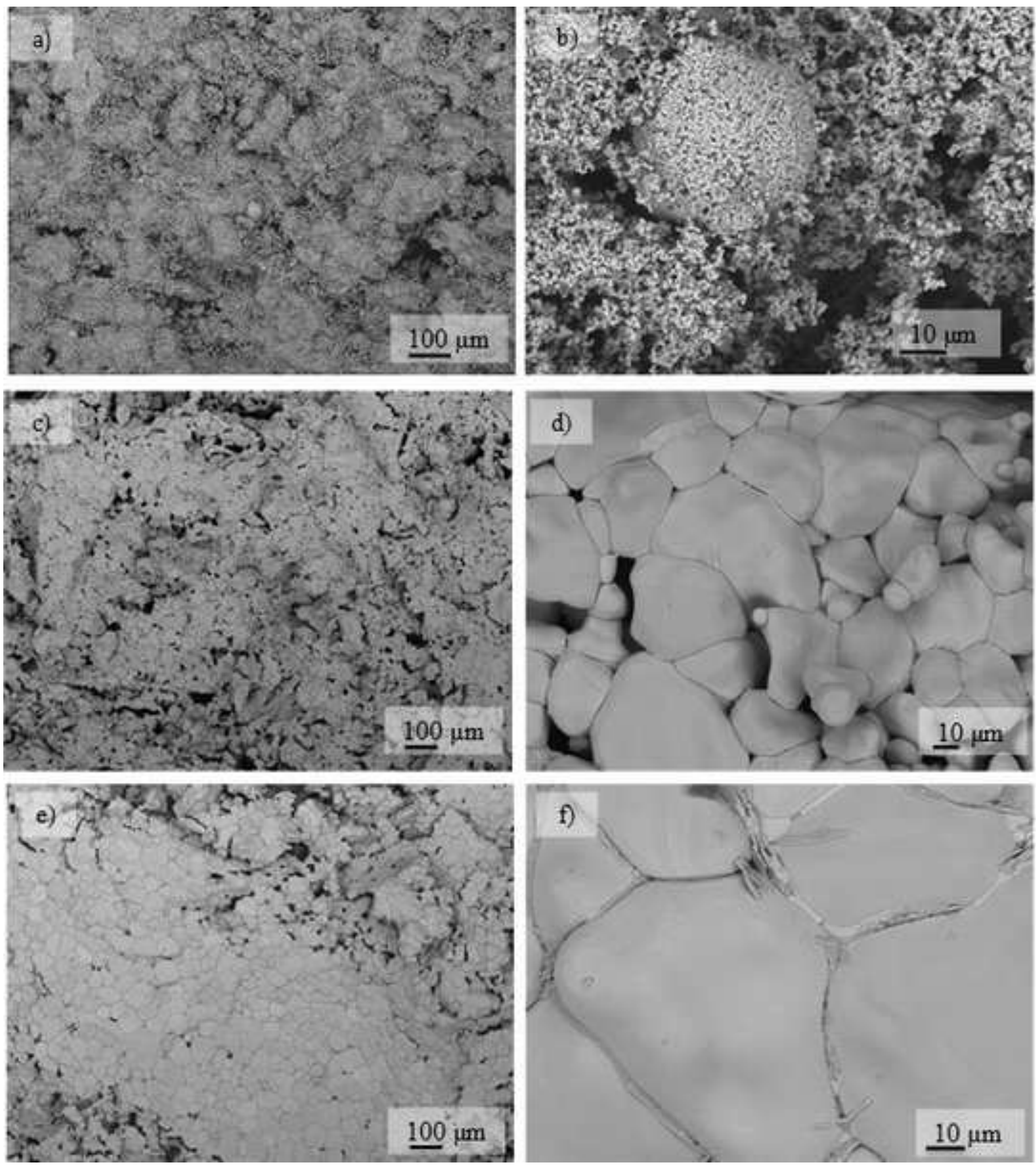
Click here to download high resolution image

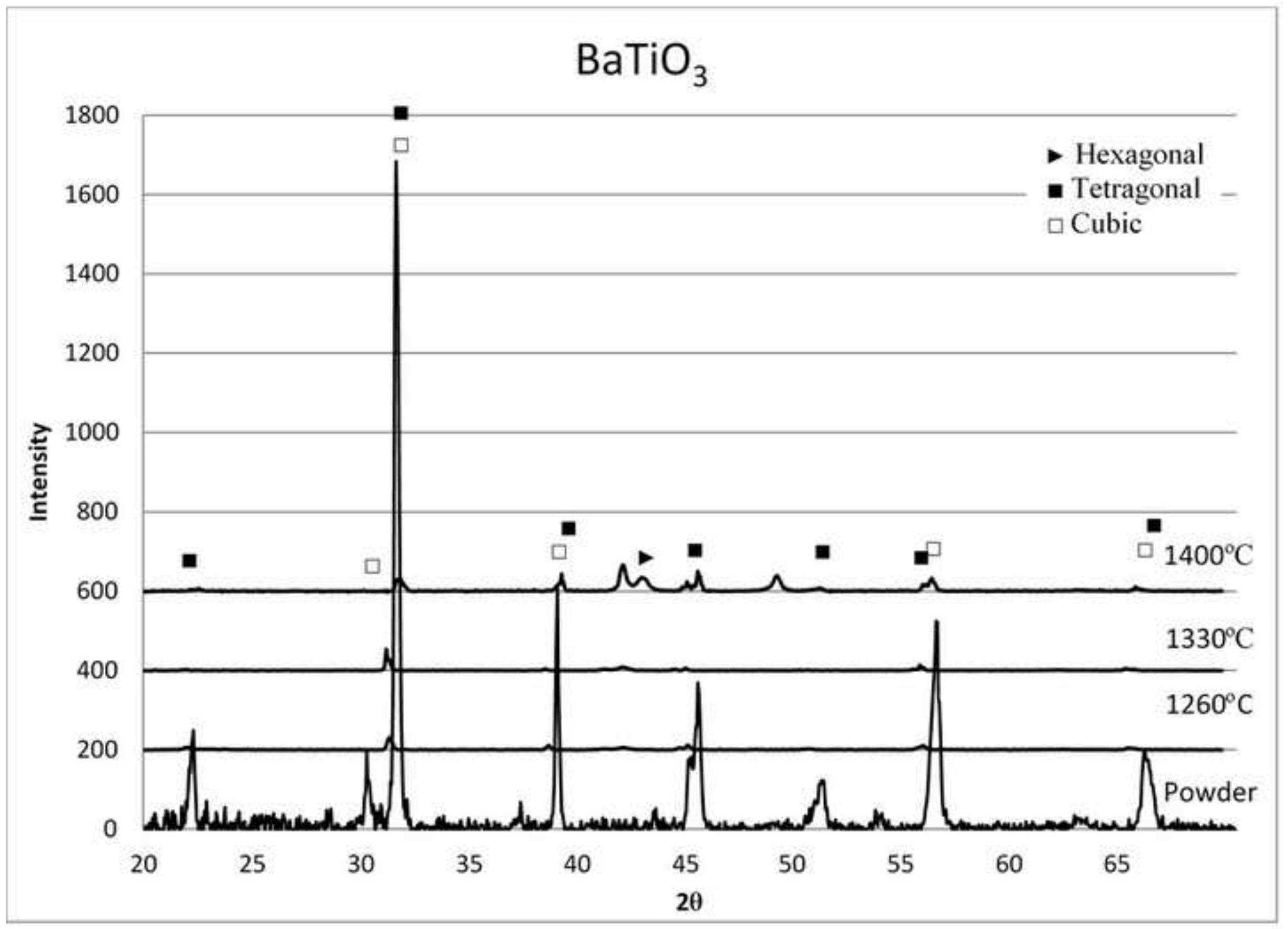


Figure 10

Click here to download high resolution image

a)

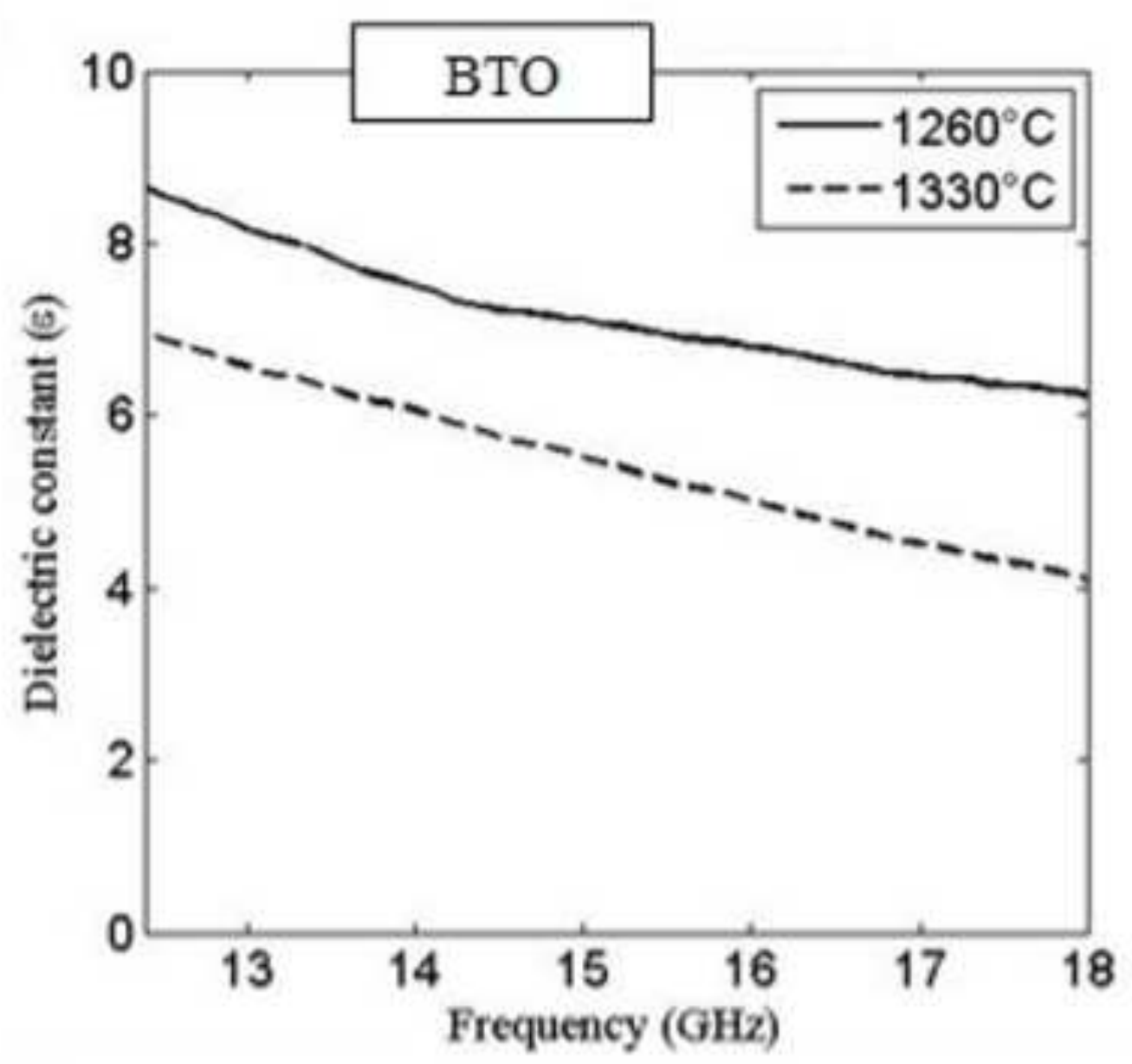

b)

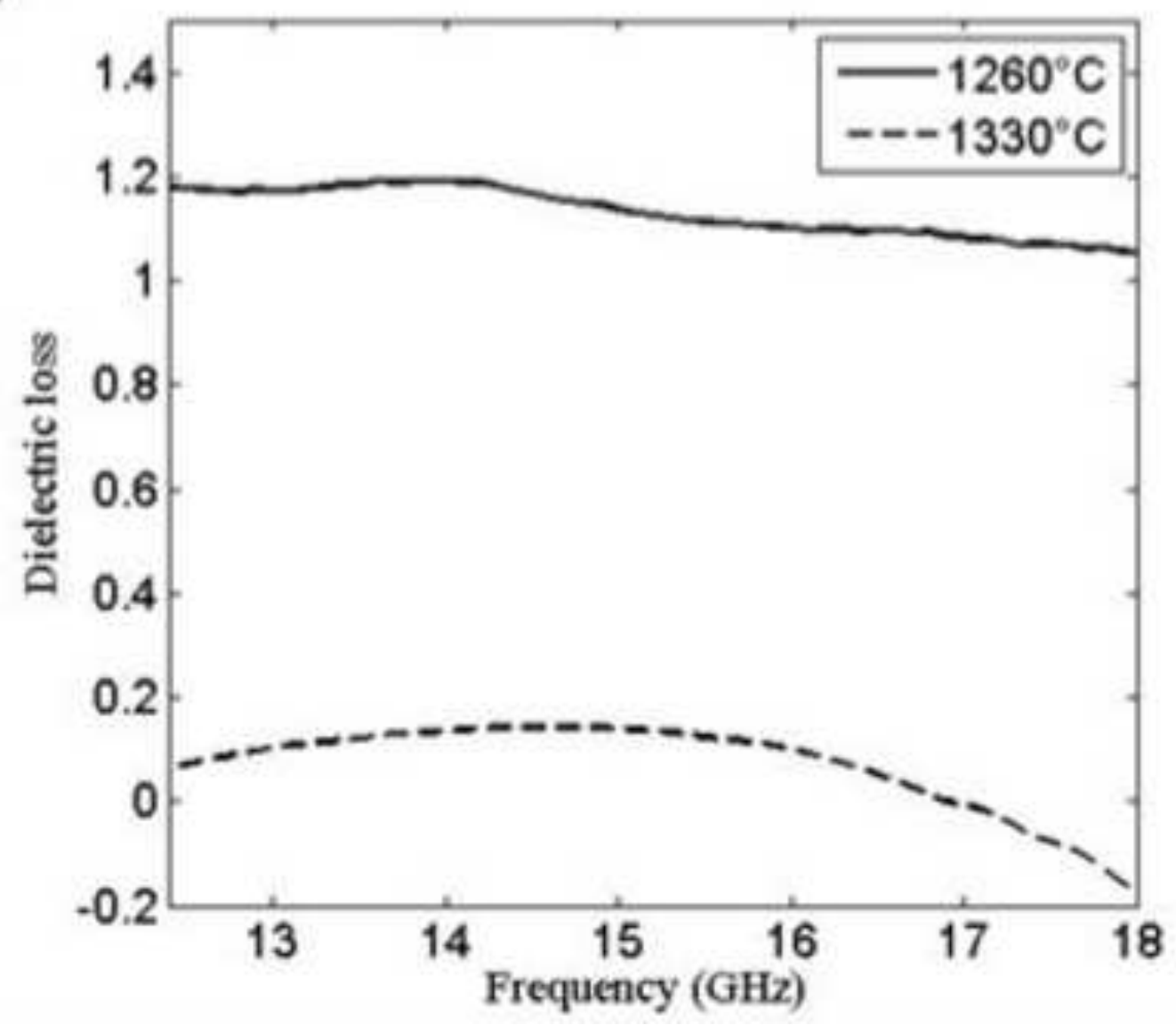


Figure 11

Click here to download high resolution image
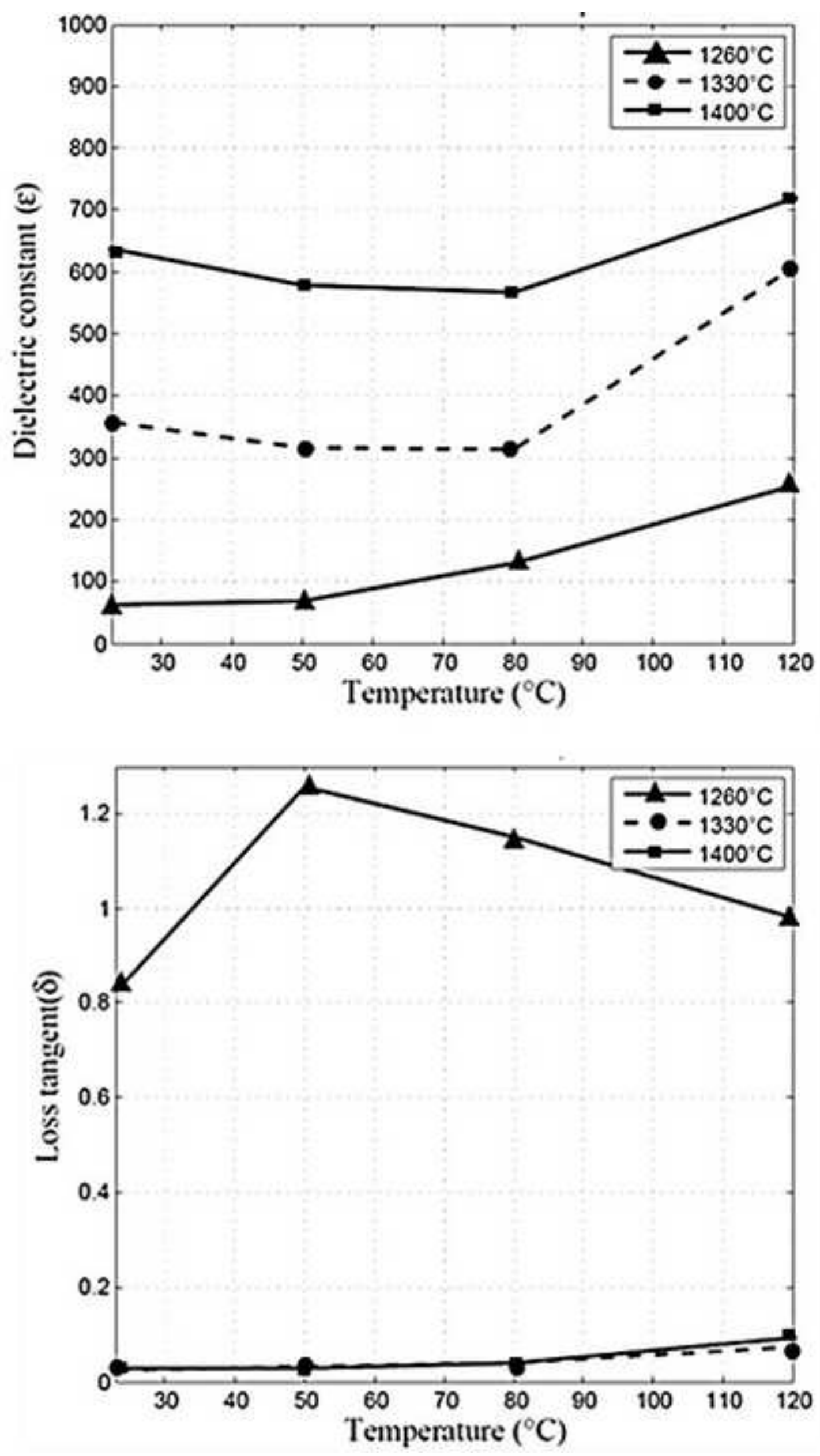